Journal of

Strategic Management

(JSM)

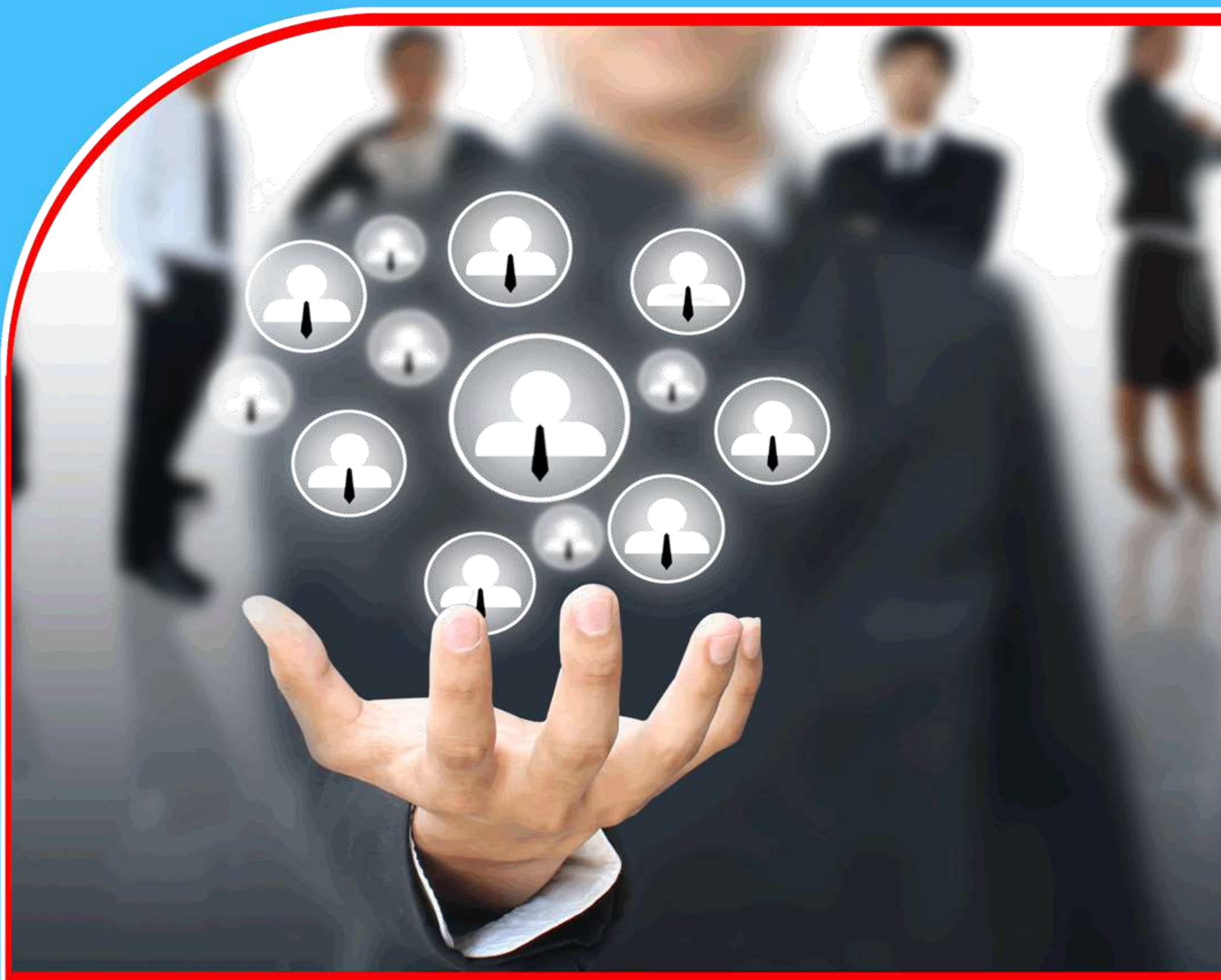

DEVOLUTION STRATEGIES IN HEALTHCARE

PROVISION AND QUALITY OF SERVICES IN HOSPITALS: THE CASE OF MBAGATHI HOSPITAL, NAIROBI COUNTY

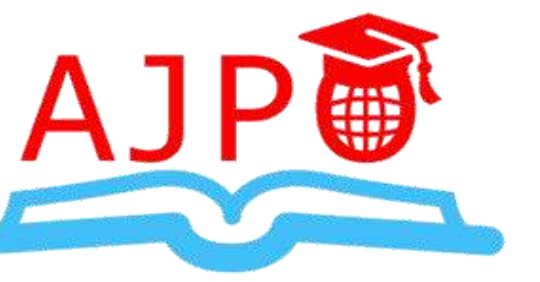




\title{
DEVOLUTION STRATEGIES IN HEALTHCARE PROVISION AND QUALITY OF SERVICES IN HOSPITALS: THE CASE OF MBAGATHI HOSPITAL, NAIROBI COUNTY
}

\author{
${ }^{1 *}$ Aviha Odari Sylvia \\ Post Graduate Student, Kenyatta University \\ *Corresponding Author's Email: sylviaodari@gmail.com \\ ${ }^{2}$ Dr. Mary Ragui \\ Lecturer, Kenyatta University
}

\begin{abstract}
Purpose: The overall objective of the study was to investigate the influence of devolution strategies on the quality of healthcare services in Nairobi City County.

Methodology: A descriptive survey research design was employed for this research. The target population was 460 staff of Mbagathi Hospital. Stratified random sampling was undertaken where a sample of 139 hospital staff was selected. The study used questionnaires to collect data from the hospital staff and observations in the hospital environment and infrastructure. The study made use of quantitative methods of data analysis by use of SPSS version 19.0 as well as descriptive and inferential analysis. Data presentation was in form of frequency tables and descriptions.

Results: The study found that human resource management, financial management, leadership and management and health infrastructure management have a positive and a significant effect on quality of healthcare services in Nairobi City County. In addition, organization culture moderates the relationship between devolution strategies and quality of healthcare services in Nairobi City County.

Unique contribution to theory, practice and policy: The study recommends that an organization should adopt devolution strategies in areas concerning human resource management, financial management, leadership and health infrastructure in order to enhance coordination and overall management of the health sector. It also recommends the government to be effective in the running of devolution strategies to ensure better health care at the county level.
\end{abstract}

Key words: devolution strategies, health sector, service quality 
Journal of Strategic Management

ISSN 2520-0461(Online)

Vol.3, Issue 1 No.5, pp 57 - 71, 2018

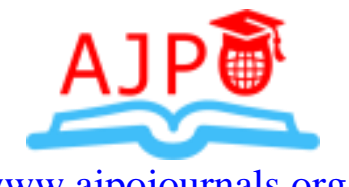

\subsection{INTRODUCTION}

\subsection{Background of the Study}

Devolution is the exchange of specialist, power and capacities from the vital to nearby experts. Devolution is acknowledged on a global basis as an essential way of enhancing conveyance of public products and enterprises. The main goal of devolution is to improve value, increment effectiveness and guarantee more investment and responsiveness of a legislature to natives. It brings about benefits as well as challenges (Grundy, Healy, Gorgolon \& Sandy, 2013).

A survey performed in the US by Pohl, Duderstadt, Tolve-Schoeneberger, Uphold, \& Hartig, (2012) on faculty practice, indicated that almost one third of the universities represented in the sample of 452 nursing faculty, had implemented a formal faculty practice plan, with many more respondents indicating that such plans were underway at their institutions.

Devolution of the health capacity additionally, displays institutional and asset allotment and usage challenges that must be managed to guarantee viable and economical social insurance benefit conveyance at the area level. The multifaceted nature of Kenya's system of devolution created worries that interruption of administrations would happen if change is not overseen well. There were fears about the areas' status to convey administrations. As indicated by the constitutional structure on devolution, obligation regarding administration of health services delivery is allocated to the districts while strategy, national referral hospitals, and limit building are the national government's duty. The function of health service delivery was formally exchanged to counties on August 9,2013, and 33\% of the aggregate reverted spending plan of Ksh.210 billion was reserved for wellbeing in the 2013/2014 spending following the exchange.

\subsection{Problem Statement}

The social pillar of Kenya's Vision 2030 national development agenda, focuses on improving the overall livelihoods of Kenyans by providing a competent and high-quality healthcare system with the best standards. Aligned to Vision 2030 is the 2012-2030 Kenya Health Policy which gives directions to the health sector in terms of recognizing and laying out important activities for achievement of health goals. This is expected to be achieved through devolution of funds and management of healthcare to the communities and health facilities at level 2, 3 and 4. Ministry of Health deals with policy and research issues. This is also aimed at reducing inequalities in access to health care.

Since healthcare services were devolved in Kenya in 2013, there have been concerns raised about implementation of the strategies. According to the Business Daily (December 2014), these concerns have been characterized by strikes by healthcare workers, nurses and doctors, which have led to intermittent paralysis of health services in public hospitals. Health workers have been agitating for improvement of terms and conditions of employment and return of human resource management function to the national government instead of county government.

From the literature review on devolution and quality of healthcare services, there existed a gap in knowledge on this area. First and foremost, Kenya has put in place a proper legal and policy framework for quality services and devolution, however, there were limited empirical studies undertaken on factors that contribute to quality health services since healthcare was devolved. 
Secondly, the few studies on devolution and healthcare in Kenya and other countries did not clearly look into the influence of devolution/decentralization on quality of health services. Thus there is knowledge gap and little indications on the influence of the healthcare devolution strategies on the quality of services from the perspective of the providers. Therefore, this study intended to bridge the knowledge gap by establishing the opinions of healthcare workers at the hospital level on devolution strategies for healthcare provision and quality of services.

\subsection{Research Objective}

The main objective of this study was to assess the participation of nursing faculty in faculty clinical practice.

The specific objectives of this study were as follows:

i. To establish the influence of devolution strategies for human resource management on the quality of health services at Mbagathi Hospital, Nairobi City County.

ii. To find out the extent to which devolution strategies for financial management influence the quality of health services at Mbagathi Hospital, Nairobi City County.

iii. To examine the influence of devolution strategies for leadership and management on the quality of health services at Mbagathi Hospital, Nairobi City County.

iv. To establish the influence of devolution strategies for health infrastructure management on the quality of health services at Mbagathi Hospital, Nairobi City County.

v. To establish the moderating effect of organizational culture on the relationship between devolution strategies and quality of health services at Mbagathi Hospital, Nairobi City County.

\subsection{THEORETICAL REVIEW}

\subsection{Theoretical Review}

\subsubsection{Agency theory}

Issues of devolution in this investigation were educated by office hypothesis. As indicated by Rees (1985), Agency hypothesis centers on the connection amongst principals and operators who practice expert for the benefit of associations. The theory is of the view that principals must explain two fundamental assignments in picking and controlling their agents. They need to choose the best agents and make instigations for them to carry on as wanted. Ayee (2005) additionally takes note of that principals need to screen the conduct of their specialists to guarantee that they are executing as concurred. In such manner, the office hypothesis is important to the connection between the National government and the County governments. In devolution of assets the foremost office relationship exists, the national government being the vital and the decayed finances administration advisory groups and staff being the specialists. On the off chance that the connection between the two gatherings isn't very much checked, at that point the issues related with the office hypothesis, similar to data asymmetries will undoubtedly happen in this manner constraining the effect of the reserve. Basic to this is irreconcilable situation. 
Journal of Strategic Management

ISSN 2520-0461(Online)

Vol.3, Issue 1 No.5, pp 57 - 71, 2018

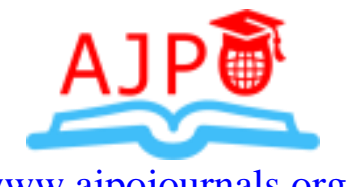

\subsubsection{New Public Management Theory}

New public management theory (NPM) as advanced by (Lane, 2002) is influencing the start of numerous changes to enhance delivery of service to the public. The essential idea of NPM can be portrayed by the new patterns in people in general organization to move some imperative bits of knowledge and qualities from the private segment system to the general population part to upgrade benefit conveyance. These incorporate productivity, adequacy, adaptability, responsiveness, rivalry, result arranged administration, more express and quantifiable execution measures, more dynamic control in view of preset yield markers and answerability. In any case, the accomplishment and disappointment stories recommend that the result of the execution of changes to enhance benefit conveyance depends on the general setting and for the most part on local possibility factors than general national attributes (Lane, 2002).

\subsection{Empirical Studies}

Ochieng (2015) looks at devolution as decentralization which connotes the exchange of certain level of formal obligation, specialist as well as assets to littler, bring down units of government as areas, locale, districts or states. According to him decentralization and by extension devolution offer considerable advantages in service delivery such as increasing effectiveness in mobilization and allocative efficiency of resources, deepening citizen participation, and improving accountability mechanisms. He further acknowledges that there is limited empirical evidence of positive outcomes of devolution

According to Elarabi and Johari (2014) the management of human resources in healthcare institutions is essential to enable the delivery of efficient and effective medical services and to achieve patient satisfaction. They established that effective management of human resources has a strong influence on quality of healthcare and improving the hospital staff's performance. Therefore, successful healthcare executives need to comprehend human conduct, work with representatives successfully, and be proficient about various frameworks and practices accessible to assemble a talented and spurred workforce. Executives should likewise know about financial, innovative, social, and lawful issues that influence HR and, thus, encourage or compel endeavors to accomplish key targets. Health care associations can pick up an upper hand by successfully dealing with their resources.

The Constitution of Kenya, Article 201 and the PFM Act sets the Principles of Public Finance Management. These include openness and accountability and promotion of equitable society through fair sharing of tax burden, fair sharing of national revenue and expenditure to promote of equitable development). These principles are expected to be observed up to the lowest level of the devolved structure such as hospital management.

Jesperste (2010) observes that fiscal decentralization lies at the core of decentralization programmes. Elements of successful fiscal decentralization include clear assignment of expenditure responsibilities, own revenue sources to local governments, institutions and procedures to ensure effective financial management. This confirms observations by GonzalezBlock et al (1989) that Mexican states that achieved decentralization were characterized by having greater financial decentralization 
According to Lowe (2010), a culture that embraces quality representatives, authority sense of duty regarding the association's kin advancement objectives and emotionally supportive networks that empower individuals to exceed expectations in their occupations is critical to quality healthcare workplace. Oyugi (2015) concurs with this view in his elaboration that leadership that is properly coordinated is a fundamental tool that if consolidated along with proper supervision and power play, will bring about the accomplishment of objectives of the healthcare system. Hence, the government needs to improve the "motivation factors" such as recognition and growth besides promoting professional identity and status of healthcare workers. This is a prerequisite for county health administration to arrive at the objectives of healthcare devolution.

Health infrastructure is any interest in physical framework, medicinal gear, data and correspondence innovation, or select transport. Dafflon and Vaillancourt (2014) observe that the availability of proper health infrastructure and medication is important for successful healthcare outcomes. Another important factor is the need for quick universal access in case of emergency since not all health needs are predictable; this requires taking into account networks interactions between roads, ambulances and facilities. Third, one must balance the benefits and costs of concentrating care in specialized care centers.

According to Mavalankar et al., (2005) infrastructure is a very essential and basic component of the delivery of health service. Ndavi et al (2009) note that availability of infrastructure including equipment, transport and communication facilities are critical in the provision of quality health care. Kenya Service Provision Assessment Survey 2004 established that majority of District health facilities in the country had the capacity to communicate with referral facility for transport during emergencies. However most of them did not have adequate medical equipment

Turner (2003) draws on Hofstede's (1994) definition of culture: '...as the collective indoctrination of the mind of a people (thinking, feeling and potential actions) differencing them from others of another group or category of people.' He further notes that organizations tend to take on particular 'corporate cultures'. Kerzner (1998) suggests that culture, though the most intangible reproductive aspect of an enterprise, wields immense influence on the manner in which services are provided.

\subsection{RESEARCH METHODOLOGY}

A descriptive survey research design was employed for this research. The target population was 460 staff of Mbagathi Hospital. Stratified random sampling was undertaken where a sample of 139 hospital staff was selected. The study used questionnaires to collect data from the hospital staff. The study made use of quantitative methods of data analysis by use of SPSS version 19.0 as well as descriptive and inferential analysis. Data presentation was in form of frequencies tables and descriptions. 


\subsection{RESULTS}

\subsection{Response rate}

The administered questionnaires were 139 all of which were duly filled and brought back. This represented an overall successful response rate of 100\%. Mugenda and Mugenda (2003) as well as Kothari (2004), stated that a reaction/response rate of over half is sufficient for an illustrative report. In light of these attestations from famous researchers, $100 \%$ reaction rate was magnificent for the examination

\subsection{Demographic Characteristics}

The study sought to establish the demographic characteristics of the respondents and the results are as shown below:

\subsubsection{Gender of the Respondent}

The respondents were requested to indicate their gender. The results were shown in figure 4.1.

\section{Gender}

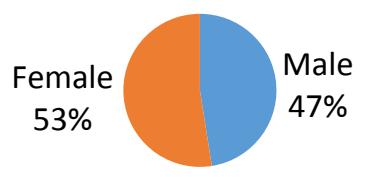

\section{Figure 1: Gender of the Respondent}

The results in figure 1 revealed that majority of the respondents $(53 \%)$ were female while $(47 \%)$ of the respondents were male. This implies that most employees of Mbagathi hospital are women. This shows that both genders were represented in the study however; there was gender disparity as it is evident that majority of the employees are women.

\subsubsection{Age Category of the Respondent}

The respondents were requested to state their age categories. The results were shown in figure 4.2.

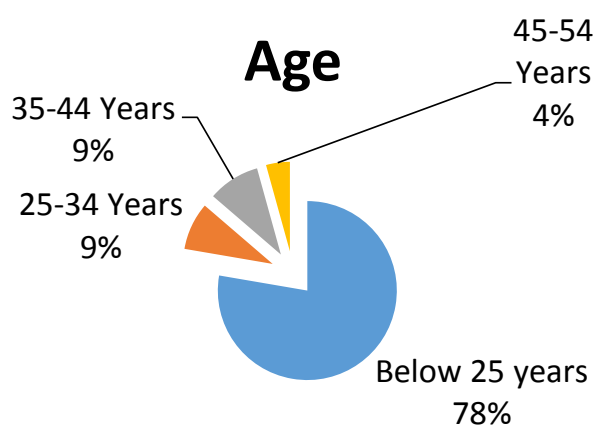

Figure 2 Age Category of the Respondent 
The result in Figure 2 revealed that majority of the respondents $(78 \%)$ were below 25 years, (9\%) of the respondents were between 25 and 34 years while another $9 \%$ were between 35 and 44 years while only (4\%) of the respondent indicated that they were between 45 and 54 years. This implied that most employees of Mbagathi hospital and young and thus they are energetic to improve the quality of the health services in the hospital.

\subsubsection{Level of Education}

The respondents were then asked to indicate their highest level of education. The results are shown in figure 3.

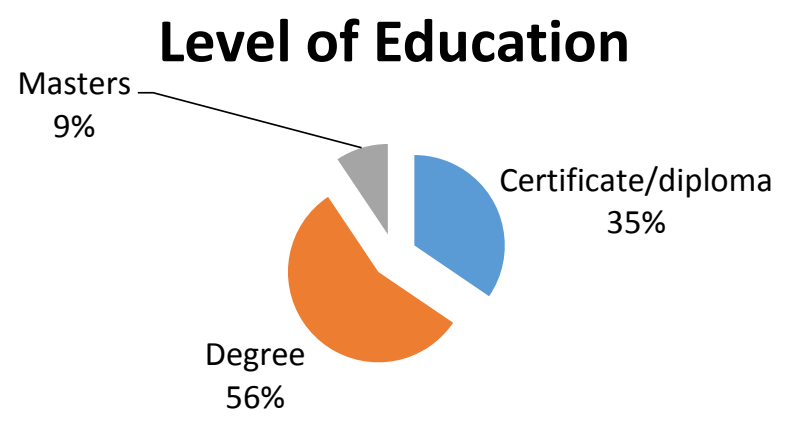

\section{Figure 4.3 Level of Education}

The result in Figure 3 revealed that majority of the respondents $(56 \%)$ were graduates with a bachelor's degree, (35\%) had certificate/diploma qualifications, (while (9\%) of the respondent indicated that they had master's degree qualifications. This implied that most employees of Mbagathi hospital are educated and thus has the capacity to improve the quality of health services in the hospital.

\subsubsection{Duration of Employment}

The respondents were further asked to indicate their duration of employment in the hospital. The results were shown in figure 4 .

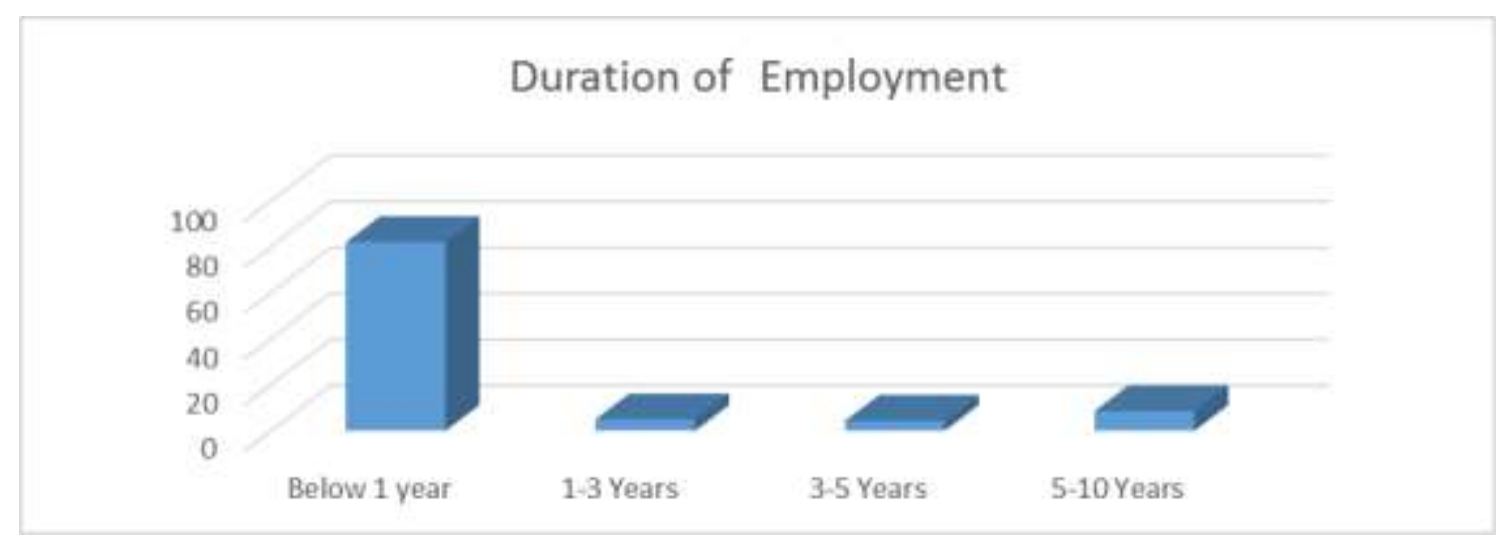

Figure 4: Duration of Employment 
The results in figure 4 revealed that majority of the respondents $(82 \%)$ were employees in Mbagathi hospital for 1 year, while $(8.6 \%)$ of the respondents were employees in the manufacturing firms for a period of 5-10 years. The results further indicated that $(5 \%)$ of the respondents worked in Mbagathi hospital for 1-3 years while (4.3\%) of the respondents had worked in the hospital for 3-5 years. This implied that most employees of Mbagathi hospital have not worked in the hospital for a long period. This might contribute to poor service delivery due to lack of relevant skills. In addition, the respondents may not give reliable information since they have not worked in the hospital for long.

\subsection{Inferential Statistics}

Inferential analysis was conducted to generate correlation results, model of fitness, and analysis of the variance and regression coefficients. Results were presented below.

\subsubsection{Correlation Analysis}

Table 1: Correlational Analysis

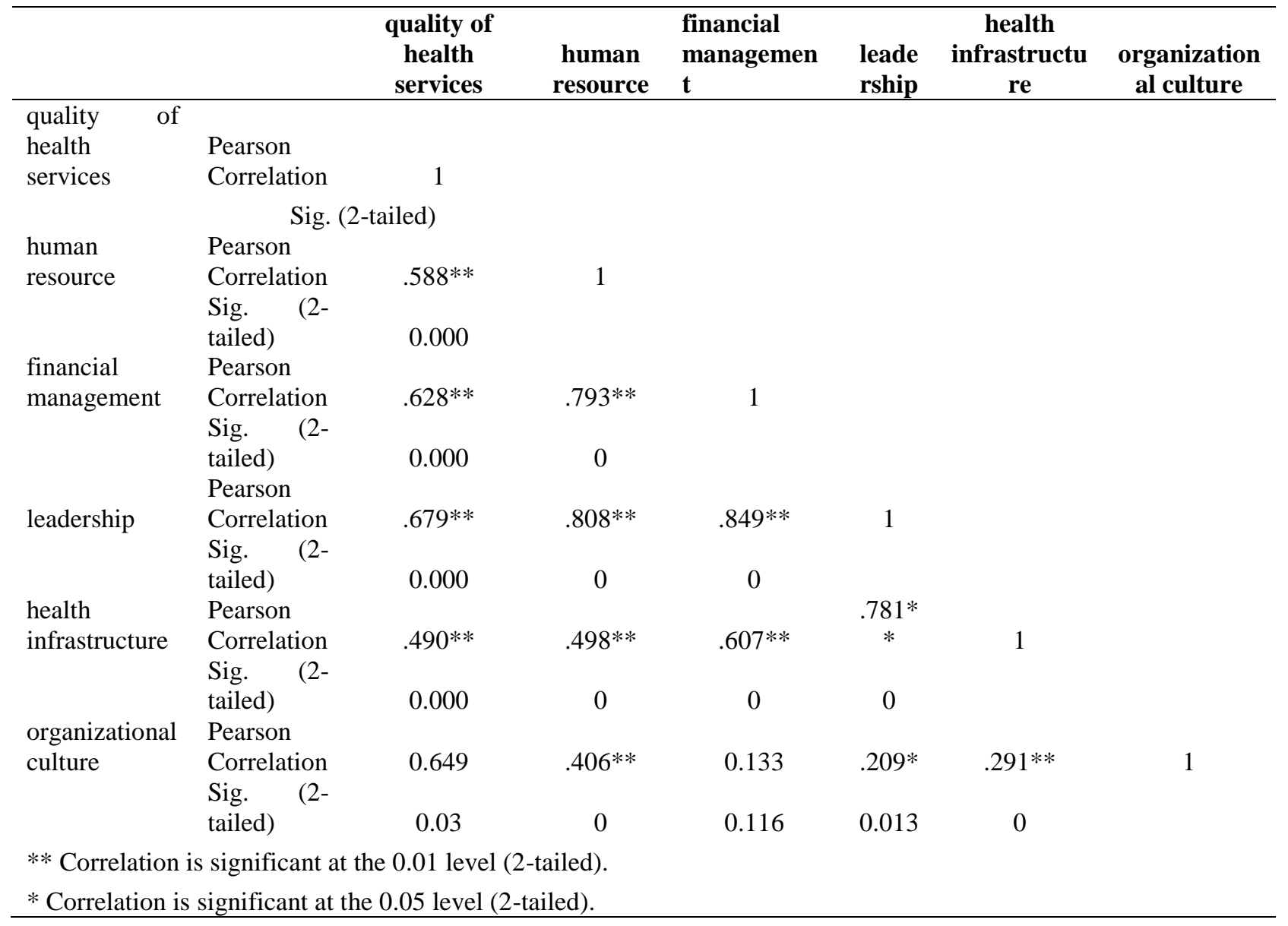

The results in table 1 revealed that there was a positive and significant association between human resource management and quality of healthcare services $(r=0.588, p=0.000)$. These findings agreed with that of Elarabi and Johari (2014) who argued that the management of 
Journal of Strategic Management

ISSN 2520-0461(Online)

Vol.3, Issue 1 No.5, pp 57 - 71, 2018

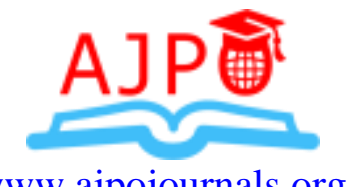

human resources in healthcare institutions is essential to enable the delivery of efficient and effective medical services and to achieve patient satisfaction.

The table further indicated that financial management and average quality of healthcare services are positively and significantly related $(\mathrm{r}=0.628, \mathrm{p}=0.000)$. These findings agreed with that of Ndavi et al (2009) who argues that adequate financial resources are critical for the sustainable provision of health services. The table further indicated that leadership and quality of healthcare services are positively and significantly related $(\mathrm{r}=0.679, \mathrm{p}=0.000)$. These findings were consistent with that of Lowe (2010) who argued that a culture that values employees, leadership commitment to the organization's people-development goals and support systems that enable people to excel in their jobs is critical to quality healthcare workplace

Similarly, results showed that health infrastructure and quality of healthcare services are positively and significantly related $(\mathrm{r}=0.490, \mathrm{p}=0.000)$. These findings agree with that of Ndavi et al (2009) who note that availability of infrastructure including equipment, transport and communication facilities are critical in the provision of quality health care. The results further, showed that organizational culture and quality of healthcare services are positively and significantly related $(r=-0.649, p=0.03)$. These findings agreed with that of Pinto (2007) who posits that organizational culture has a great influence on departmental approach and employee dedication to quality service provision.

\subsubsection{Regression Analysis before Moderation}

Table 2: Model Fitness before Moderation

\begin{tabular}{|c|c|c|c|c|}
\hline Model & $\mathbf{R}$ & R Square & Adjusted R Square & Std. Error of the Estimate \\
\hline & $.686 a$ & 0.471 & 0.455 & 0.633 \\
\hline
\end{tabular}

The results in table 4.2 presented the fitness of model of regression model used in explaining the study phenomena. Human resource management, financial management, leadership and health infrastructure were found to be satisfactory variables in quality of healthcare services. This was supported by coefficient of determination that is the $\mathrm{R}$ square of $45.5 \%$. This shows that human resource management, financial management, leadership and health infrastructure explain $45.5 \%$ of the quality of healthcare services. The results meant that the model applied to link the relationship of the variables was satisfactory.

Table 3: Analysis of Variance (ANOVA) before Moderation

\begin{tabular}{lccccc}
\hline & Sum of Squares & df & Mean Square & F & Sig. \\
\hline Regression & 47.369 & 4 & 11.842 & 29.555 & $\mathbf{0 . 0 0 0}$ \\
Residual & 53.291 & 134 & 0.401 & & \\
Total & 100.66 & 138 & & & \\
\hline
\end{tabular}

Table 3 provided the results on the analysis of the variance (ANOVA). The results indicated that the overall model was statistically significant. Further, the results implied that the independent variables are good predictors of quality of healthcare services. This was supported by an F 
Journal of Strategic Management

ISSN 2520-0461(Online)

Vol.3, Issue 1 No.5, pp 57 - 71, 2018

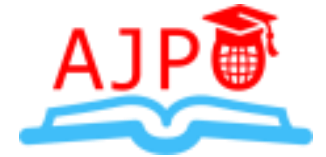

www.ajpojournals.org

statistic of 29.555 and the reported $p$ value (0.000) which was less than the conventional probability of 0.05 significance level.

Table 4: Regression of coefficients before Moderation

\begin{tabular}{lcccc}
\hline & $\boldsymbol{\beta}$ & Std. Error & $\mathbf{t}$ & Sig. \\
\hline (Constant) & 1.79 & 0.317 & 5.646 & 0.000 \\
human resource management & 0.345 & 0.115 & 4.017 & $\mathbf{0 . 0 0 0}$ \\
financial management & 0.501 & 0.124 & 5.569 & $\mathbf{0 . 0 0 0}$ \\
leadership & 0.455 & 0.159 & 2.855 & $\mathbf{0 . 0 0 5}$ \\
health infrastructure & 0.729 & 0.121 & 9.039 & $\mathbf{0 . 0 3 0}$ \\
\hline
\end{tabular}

Regression of coefficients results in table 4.4 revealed that human resource management and quality of healthcare services are positively and insignificant related $(r=0.345, p=0.000)$. These findings agreed with that of Elarabi and Johari (2014) who argued that the management of human resources in healthcare institutions is essential to enable the delivery of efficient and effective medical services and to achieve patient satisfaction. The table further indicates that financial management and quality of healthcare services are positively and insignificant related $(\mathrm{r}=0.501, \mathrm{p}=0.000)$. These findings agreed with that of Ndavi et al (2009) who argues that adequate financial resources are critical for the sustainable provision of health services.

It was further established that leadership and quality of healthcare services were positively and significantly related $(\mathrm{r}=0.455, \mathrm{p}=0.005)$. These findings were consistent with that of Lowe (2010) who argued that a culture that values employees, leadership commitment to the organization's people-development goals and support systems that enable people to excel in their jobs is critical to quality healthcare workplace. In addition, health infrastructure and quality of healthcare services were positively and significantly related $(r=0.729, p=0.030)$. These findings agree with that of Ndavi et al (2009) who note that availability of infrastructure including equipment, transport and communication facilities are critical in the provision of quality health care.

Service quality $=1.79+0.345$ human resource management +0.501 financial management + 0.455 leadership +0.729 health infrastructure

\subsubsection{Regression Analysis after Moderation}

The fifth objective of the study was to establish the moderating effect of organizational culture on the relationship between devolution strategies and quality of health services at Mbagathi Hospital, Nairobi City County.

Table 5: Model of Fitness after Moderation

\begin{tabular}{|c|c|c|c|c|}
\hline Model & $\mathbf{R}$ & R Square & Adjusted R Square & Std. Error of the Estimate \\
\hline & 0.75 & 0.5625 & 0.5518 & 0.83308 \\
\hline
\end{tabular}


Journal of Strategic Management

ISSN 2520-0461(Online)

Vol.3, Issue 1 No.5, pp 57 - 71, 2018

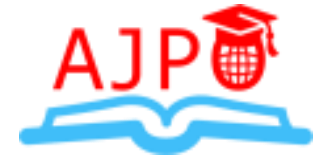

www.ajpojournals.org

The results in table 5 presented the fitness of model of regression model used in explaining the study phenomena. The $\mathrm{R}$ squared before control was $47.1 \%$. The $\mathrm{R}$ squared after control increased from $47.1 \%$ to $56.26 \%$. This implies that organization culture moderates the relationship between devolution strategies and quality of healthcare services in Nairobi City County.

Table 6: Analysis of Variance (ANOVA)

\begin{tabular}{lccccc}
\hline & Sum of Squares & df & Mean Square & F & Sig. \\
\hline Regression & 3.44 & 1 & 3.44 & 34.781 & $\mathbf{0 . 0 3 0}$ \\
Residual & 98.568 & 137 & 0.719 & & \\
Total & 102.008 & 138 & & & \\
\hline
\end{tabular}

Table 4.6 provided the results on the analysis of the variance (ANOVA). The results indicated that the overall model was statistically significant. Further, the results implied that the moderating variables are good predictors of quality of healthcare services. This was supported by an F statistic of 29.555 and the reported $p$ value (0.000) which was less than the conventional probability of 0.05 significance level. However the $\mathrm{F}$ statistic increased after moderation from 29.555 to 34.781 .

Table 7: Regression of coefficients

\begin{tabular}{lccccc}
\hline & B & Std. Error & Beta & t & Sig. \\
\hline (Constant) & 3.602 & 0.119 & & 30.28 & 0 \\
$\begin{array}{l}\text { X_1(Moderated } \\
\text { Variables) }\end{array}$ & 0.008 & 0.004 & 0.184 & 2.187 & 0.03 \\
\hline
\end{tabular}

The results revealed that the $\mathrm{P}$ value after moderation was significant $(\mathrm{p}=0.03)$. This implied that organization culture moderates the relationship between devolution strategies and quality of healthcare services in Nairobi City County. These findings agreed with that of Pinto (2007) who posits that organizational culture has a great influence on departmental approach and employee dedication to quality service provision.

Service quality $=3.602+0.008$ devolution strategies $*$ organization culture

\subsection{DISCUSSIONS, CONCLUSIONS AND RECOMMENDATIONS}

\subsection{Discussion}

The first objective was to establish the influence of devolution strategies for human resource management on the quality of health services at Mbagathi Hospital, Nairobi City County. The findings from the regression revealed that human resource management had a positive and significant effect on the quality of health services at Mbagathi Hospital $(r=0.345, p=0.000)$. The second objective to find out the extent to which devolution strategies for financial management influence the quality of health services at Mbagathi Hospital, Nairobi City County. The findings revealed a significant relationship between financial management and the quality of health services. The findings from the regression revealed that financial management had a positive and 
Journal of Strategic Management

ISSN 2520-0461(Online)

Vol.3, Issue 1 No.5, pp 57 - 71, 2018

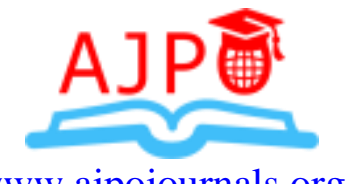

significant effect on the quality of health services $(r=0.501, p=0.000)$. The third objective was to examine the influence of devolution strategies for leadership and management on the quality of health services at Mbagathi Hospital, Nairobi City County. There also existed a significant relationship between leadership and management and the quality of health services The findings from the regression revealed that leadership and management had a positive and significant effect on the quality of health services $(r=0.455, \mathrm{p}=0.005)$.

The fourth objective of the study was to establish the influence of devolution strategies for health infrastructure management on the quality of health services at Mbagathi Hospital, Nairobi City County. The results showed a significant association between health infrastructure management and the quality of health services. Regression results revealed a positive and significant effect between health management of infrastructure and the quality of health services $(r=0.729$, $\mathrm{p}=0.030$ ). The fifth objective was to establish the influence of moderating effect of organizational culture on the relationship between devolution strategies and quality of health services at Mbagathi Hospital, Nairobi City County. The findings revealed that organizational culture moderates the relationship between devolution strategies and quality of health services at Mbagathi Hospital, Nairobi City County.

\subsection{Conclusions}

The study concluded that human resource management has a positive and a significant effect on quality of healthcare services. In addition, the study also concluded that human resource management is essential in the quality of health services because of its ability to influence the human factor of the hospital.

The study also concluded that financial management has a positive and a significant effect on quality of healthcare services. Financial management has an impact on the quality of health services, since it facilitates the running of the organization in monetary terms.

The study also concluded that leadership management has a positive and a significant effect on quality of healthcare services. Leadership is very critical as to drive the hospital's overall objectives towards its mission, vision and culture/values. This is an important factor in providing an oversight role throughout the departmental procedures in the hospital.

The study also concluded that health infrastructure have a positive and a significant effect on quality of healthcare services. Health infrastructure is essential in the providing of quality health services as the right equipment availability in the hospital are essential in the running of the activities. Health infrastructure has a positive effect on the overall health services. The values and conducts of the organization are very critical in setting the standards of procedures and services and as such they offer a base for overall quality in health services, and if not properly managed or stated, they could lead to an overall decline in the service delivery of any institution

\subsection{Recommendations}

The study also recommends that the national and county government should provide the public hospitals with adequate funding so as they can be able to deliver quality services to the citizens. In addition, the funds should be provided on timely basis. Staff including doctors, nurses and clinicians should have basic knowledge and skill in financial and budgetary management 
Journal of Strategic Management

ISSN 2520-0461(Online)

Vol.3, Issue 1 No.5, pp 57 - 71, 2018

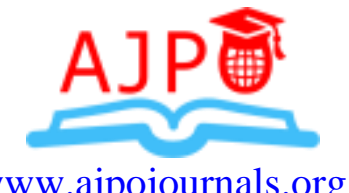

There is need for a strategic approach in management of the healthcare sector at macro-level as well as micro-level. The management of hospitals under the county governments should put into considerations all the factors that affect healthcare service provision including but not limited to human resource management, funding and financial management, governance and leadership, healthcare infrastructure- facilities and equipment and organizational culture. There is also need to ensure conducive environment through political good will at national and county government level to address a myriad of emerging issues in the health sector. The leadership at these levels should also be well coordinated for proper decision making.

\section{REFERENCES}

Ayee. J. R. (2005). Public Sector Management in Africa

Dafflon, B., \& Vaillancourt, F. (2014). Investing in health infrastructure: how decentralization matters (No. paper1411). International Center for Public Policy, Andrew Young School of Policy Studies, Georgia State University.

Elarabi, H., \& Johari, F. (2014). The impact of human resources management on healthcare quality. Asian Journal of Management Sciences and Education Vol. 3, No. 1.

Grundy, J., Healy, V., Gorgolon, L., \& Sandig, E. (2013). Overview of devolution of health services in the Philippines. Rural Remote Health, 3(2), 220.

Jesperste, P. (2010). Source material on decentralization and improved service delivery for the poor.Danida

Kerzner, H. (1998). In search of excellence in project management. Van Nostrand Reinhold.

Lowe, G., \& Chan, B. (2010). Using common work environment metrics to improve performance in healthcare organizations. Healthc Pap, 10, 43-47.

Mugenda, O., \& Mugenda, A. (2003). Research methodology: qualitative and quantitative techniques.

Ndavi, P. M., Ogola, S., Kizito, P. M., \& Johnson, K. (2009). Decentralizing Kenya's Health Management System: An Evaluation. Calverton, Maryland, USA.

Ndavi, P. M., Ogola, S., Kizito, P. M., \& Johnson, K. (2009). Decentralizing Kenya's Health Management System: An Evaluation. Calverton, Maryland, USA.

Nicholas, D., Huntington, P., Williams, P., \& Dobrowolski, T. (2004). Re-appraising information seeking behaviour in a digital environment: bouncers, checkers, returnees and the like. Journal of Documentation, 60(1), 24-43. 
Oyugi, B. (2015). Potential Impact of Devolution on Motivation and Job Satisfaction of Healthcare Workers in Kenya: Lessons from early implementation in Kenya and experiences of other Sub-Saharan African Countries. Journal of Global healthcare systems, Volume 5, Number 1.

Rees, R., (1985). The Theory of Principal and Agent-Part II. Bulletin of Economic Research, 37(2), 75-97. 